\title{
Childhood maternal care is associated with DNA methylation of the genes for brain-derived neurotrophic factor (BDNF) and oxytocin receptor (OXTR) in peripheral blood cells in adult men and women
}

\author{
Eva Unternaehrer ${ }^{1,2,3}$, Andrea Hans Meyer ${ }^{1}$, Susan C. A. Burkhardt ${ }^{2,4}$, Emma Dempster $^{5}$, Simon Staehli ${ }^{1,6}$, \\ Nathan Theill ${ }^{7}$, Roselind Lieb ${ }^{1,2}$, and Gunther Meinlschmidt ${ }^{1,2,8}$ \\ ${ }^{1}$ Department of Psychology, Division of Clinical Psychology and Epidemiology, University of Basel, Basel, Switzerland, ${ }^{2}$ National Center of \\ Competence in Research (NCCR), Swiss Etiological Study of Adjustment and Mental Health (sesam), University of Basel, Switzerland, ${ }^{3}$ Douglas \\ Mental Health University Institute, McGill University, Montréal, Canada, ${ }^{4}$ Department of Research \& Development, University of Applied Sciences in \\ Special Needs Education, Zürich, Switzerland, ${ }^{5}$ University of Exeter Medical School, Exeter University, Exeter, UK, ${ }^{6}$ Institute of Psychobiology, \\ University of Trier, Trier, Germany, ${ }^{7}$ Division of Psychiatry Research, University of Zurich, Zurich, Switzerland, and ${ }^{8}$ Faculty of Medicine, Ruhr- \\ University Bochum, Germany
}

\begin{abstract}
In adults, reporting low and high maternal care in childhood, we compared DNA methylation in two stress-associated genes (two target sequences in the oxytocin receptor gene, OXTR; one in the brain-derived neurotrophic factor gene, BDNF) in peripheral whole blood, in a cross-sectional study (University of Basel, Switzerland) during 2007-2008. We recruited 89 participants scoring $<27$ ( $n=47,36$ women) or $>33$ ( $n=42,35$ women) on the maternal care subscale of the Parental Bonding Instrument (PBI) at a previous assessment of a larger group $(N=709$, range PBI maternal care $=0-36$, age range $=19-66$ years; median 24 years). 85 participants gave blood for DNA methylation analyses (Sequenom ${ }^{\mathrm{R}}$ EpiTYPER, San Diego, CA) and cell count (Sysmex PocH$100 \mathrm{i}^{\mathrm{TM}}$, Kobe, Japan). Mixed model statistical analysis showed greater DNA methylation in the low versus high maternal care group, in the BDNF target sequence [Likelihood-Ratio (1) = 4.47; $p=0.035]$ and in one OXTR target sequence Likelihood-Ratio $(1)=4.33 ; p=0.037$ ], but not the second OXTR target sequence [Likelihood-Ratio (1) $<0.001 ; p=0.995$ ). Mediation analyses indicated that differential blood cell count did not explain associations between low maternal care and BDNF (estimate $=-0.005,95 \% \mathrm{Cl}=-0.025$ to $0.015 ; p=0.626$ ) or OXTR DNA methylation (estimate $=-0.015,95 \% \mathrm{Cl}=-0.038$ to $0.008 ; p=0.192$ ). Hence, low maternal care in childhood was associated with greater DNA methylation in an OXTR and a BDNF target sequence in blood cells in adulthood. Although the study has limitations (cross-sectional, a wide age range, only three target sequences in two genes studied, small effects, uncertain relevance of changes in blood cells to gene methylation in brain), the findings may indicate components of the epiphenotype from early life stress.
\end{abstract}

\section{Keywords}

$B D N F$, brain-derived neurotrophic factor, early life adversities, epigenetics, OXTR, oxytocin receptor, parental care, white blood cells

\section{Introduction}

Parental care is crucial for the establishment of mental health for the offspring across life. Experiencing poor parental care during childhood increases the risk of abnormal psychological and endocrine responses to stress (Albers et al., 2008; Engert et al., 2010), abnormal neuronal functioning (Belsky \& de Haan, 2011) and mental disorders later in life (Bowlby, 1969; Enns et al., 2002; Knappe et al., 2012). The molecular pathway underlying these associations is not yet fully elucidated. Increasing evidence suggests that early adverse experiences, especially low maternal care, alter DNA

Correspondence: Dr Gunther Meinlschmidt, PhD, Department of Psychology, Division of Clinical Psychology and Epidemiology, University of Basel, Missionsstrasse 60/62, 4055 Basel, Switzerland. Tel: +41 $61 \quad 267 \quad 09$ 61. Fax: +41 $61 \quad 267 \quad 06$ 59. E-mail: gunther.meinlschmidt@unibas.ch methylation with disadvantageous consequences for behavior and health later in life (Zhang et al., 2013).

DNA methylation is an epigenetic mechanism, by which a methyl-group covalently attaches to typically a cytosine followed by a guanine $(\mathrm{CpG})$ in the DNA strand (Auclair \& Weber, 2012). Several rodent studies found aberrant DNA methylation of stress-related genes in brain tissue of offspring exposed to an adverse early (maternal) environment (Champagne et al., 2006; McGowan et al., 2011; Murgatroyd et al., 2009; Roth et al., 2009; Weaver et al., 2004; Zhang et al., 2010). Recent human studies on epigenetic consequences of early life stress suggest similar processes. In post-mortem brain tissue, DNA methylation of the glucocorticoid receptor gene $(N R 3 C l)$ and promoter regions of several other genes differed between suicide victims, who experienced childhood abuse compared to subjects without these experiences (McGowan et al., 2008, 
2009). In human peripheral blood, individuals who experienced early life stress, including low maternal warmth and affection, showed differences in DNA methylation of stressrelated genes compared to those without this experience (Bick et al., 2012; Kerschensteiner et al., 1999; Naumova et al., 2012; Perroud et al., 2011, 2013; Tyrka et al., 2012). Taken together, these studies suggest that early life adversities are associated with long-term changes in DNA methylation of stress-associated genes. Thus, investigating additional stressrelated candidate genes could extend our understanding of an epiphenotype of early life stress in humans.

In our study, we investigated the brain-derived neurotrophic factor gene $(B D N F)$ as a first candidate gene. $B D N F$ encodes for a neuronal growth factor involved in neuronal development, -plasticity and -protection and is expressed in neurons as well as in peripheral blood mononuclear cells (Binder \& Scharfman, 2004; Kerschensteiner et al., 1999). Epigenetic studies in rodents have shown that early life stress resulted in a higher DNA methylation status of BDNF in neuronal tissue (Roth et al., 2009). Moreover, results from clinical studies suggest an involvement of increased $B D N F$ DNA methylation in the etiology of stress-related mental disorders in humans (D'Addario et al., 2012; Dell'Osso et al., 2014; Fuchikami et al., 2011; Kang et al., 2013; Keller et al., 2010; Perroud et al., 2013). Notably, Perroud et al. (2013) reported early maltreatment-related changes in $B D N F$ DNA methylation measured in peripheral blood cells. This indicates that BDNF DNA methylation measured in the periphery could be sensitive to environmental cues, which is also supported by a recent finding in mice demonstrating associations of BDNF DNA methylation between neurons and blood cells (Kundakovic et al., 2015).

The oxytocin receptor gene $(O X T R)$ was included as a second candidate gene, because oxytocin signaling modulates the stress response centrally as well as peripherally (Carter, 2003; Petersson et al., 1999; Uvnas-Moberg, 1998) and plays a crucial role in maternal behaviors (Russell et al., 2003). Furthermore, the oxytocin system seems to be sensitive to stress experiences (Heim et al., 2009; Meinlschmidt \& Heim, 2007). Finally, OXTR DNA methylation measured in peripheral blood samples could be linked to brain activity and behavior (Cecil et al., 2014; Dadds et al., 2014; Gregory et al., 2009; Jack et al., 2012).

Based on these findings, the aim of this study was to examine an association between maternal care during childhood and DNA methylation in the BDNF and OXTR in human peripheral blood. We compared DNA methylation in one target sequence (TS) in $B D N F$ and two target sequences in OXTR (referred to as $B D N F_{T S}, O X T R_{T S 1}$ and $O X T R_{T S 2}$ ) between adults reporting high versus low maternal care during childhood and adolescence. We hypothesized that DNA methylation would differ between adults reporting low compared to those reporting high maternal care during childhood. Because DNA methylation was shown to be blood cell type specific for certain loci (Adalsteinsson et al., 2012) and early life adversities are associated with changes in blood cell distribution (Surtees et al., 2003), we estimated the effect of differential blood cell count as a potential mediator in the association between maternal care and DNA methylation. Specifically, we hypothesized that differential blood cell count would mediate a potential association between maternal care and DNA methylation of the investigated target sequences. Confirmation of this hypothesis could indicate that maternal care-associated differences in DNA methylation are secondary to differences in blood cell count.

\section{Methods}

\section{Participants and procedure}

The initial sample of this cross-sectional study consisted of 89 adults. They were selected from an ad-hoc sample comprising 709 university students, who were recruited at a preliminary screening conducted at the University of Basel in 2007. All participants completed the Parental Bonding Instrument (PBI) (Parker et al., 1979) and gave written informed consent. Those participants who scored below a cut-off of 27 or above 33 on the subscale maternal care of the PBI were invited to a personal appointment. As we recruited participants from a generally highly functioning target population we did not apply any specific exclusion criteria. All appointments took place at the facilities of the University of Basel, Switzerland, from late 2007 to early 2008. Participants were asked to arrive to the laboratory with fasting between 08:00 h and 09:00 h. After written informed consent was obtained, a study nurse took two blood samples of $2.7 \mathrm{ml}$ each, from a brachial vein, at room temperature using EDTA Monovettes (Sarstedt, Nümbrecht) for DNA extraction and blood cell count. Thereafter, participants completed questionnaires on sociodemographic data and medical history. The study was approved by the local ethics committee, Basel (Ethikkommission beider Basel, EKBB) and was carried out in accordance with the latest version of the Declaration of Helsinki.

Blood samples of four participants could not be analyzed due to a lack of blood sample, hence these participants were excluded from all subsequent analyses. The participants' sociodemographic characteristics are depicted in Table 1 and a flow chart of study participation is given in Figure 1. The resulting sample consisted of 85 participants: 45 reported low (34 were females), 40 high maternal care (33 were females). Women $(n=67)$ and men $(n=18)$ were equally distributed between the maternal care groups $\left(\chi^{2}(1)=0.612, p=0.59\right)$. Age ranged from 19 to 66 years in the low care group and from 20 to 46 years in the high care group with an overall mean age of 27.5 years $(S D=8.4$ years, $95 \%$ confidence interval $=25.6-29.3$ years) and median age of 24 years. Age range is illustrated in supplementary Figure S1. All participants were of European origin.

\section{Maternal care}

Maternal care was assessed using the PBI (Parker et al., 1979), which measures maternal care during the first 16 years of life on 12 items. Participants responded on a 4-point Likert scale to which extent different statements about perceived maternal care applied $(0=$ not true; $3=$ very true $)$, with high scores indicating high-caring mothers. Although the PBI not only assesses maternal care, but also maternal overprotection, we focused on the dimension of maternal care and recruited participants when scoring below a cut-off of 27 or above a cut-off of 33 on the respective subscale in a 
Table 1. Sociodemographics and group characteristics for participants reporting low or high maternal care on the PBI.

\begin{tabular}{|c|c|c|c|c|}
\hline & \multicolumn{2}{|c|}{ Low maternal care $(n=45)$} & \multicolumn{2}{|c|}{ High maternal care $\quad(n=40)$} \\
\hline & $M$ & $95 \% \mathrm{CI}$ & $M$ & $95 \% \mathrm{CI}$ \\
\hline Age (years)* & 30.3 & $27.3-33.2$ & 24.3 & $22.7-25.9$ \\
\hline Body mass index $\left(\mathrm{kg} / \mathrm{m}^{2}\right)^{*}$ & 23.6 & $22.5-24.7$ & 21.6 & $20.5-22.6$ \\
\hline Sum score on PBI* & 16.5 & $14.7-18.2$ & 35.1 & $34.9-35.3$ \\
\hline \multicolumn{5}{|l|}{ Blood cell count } \\
\hline Lymphocytes (\%) & 33.5 & $31.2-35.9$ & 31.7 & $29.6-33.9$ \\
\hline Neutrophils $(\%)^{\mathrm{a}}$ & 58.3 & $55.6-61.0$ & 60.4 & $57.6-63.1$ \\
\hline \multirow[t]{2}{*}{ Middle sized leukocytes ${ }^{\mathrm{b}}(\%)^{\mathrm{a}}$} & 11.1 & $6.7-15.5$ & 7.9 & $6.5-9.3$ \\
\hline & $N$ & $\%$ & $N$ & $\%$ \\
\hline \multicolumn{5}{|l|}{ Education $^{\mathrm{c}}$} \\
\hline Primary school & 3 & 6.7 & 0 & 0 \\
\hline Apprenticeship & 5 & 11.1 & 0 & 0 \\
\hline Business school & 2 & 4.4 & 1 & 2.5 \\
\hline Technical school & 2 & 4.4 & 0 & 0 \\
\hline Matura (high school) & 22 & 48.9 & 31 & 77.5 \\
\hline University/College & 11 & 24.4 & 14 & 35 \\
\hline \multicolumn{5}{|l|}{ Income per month* } \\
\hline Less than CHF 225 & 6 & 13.3 & 16 & 40 \\
\hline Between CHF 225-750 & 7 & 15.6 & 10 & 25 \\
\hline Between CHF 750-1500 & 10 & 22.2 & 8 & 20 \\
\hline Between CHF 1500-3000 & 11 & 24.4 & 3 & 7.5 \\
\hline Between CHF 3000-4500 & 4 & 8.9 & 0 & 0 \\
\hline Between CHF 4500-7500 & 2 & 4.4 & 1 & 2.5 \\
\hline Between CHF 7500-11,250 & 4 & 8.9 & 1 & 2.5 \\
\hline More than CHF 11,250 & 1 & 2.2 & 0 & 0 \\
\hline \multicolumn{5}{|l|}{ Main occupation* } \\
\hline Undergraduate student & 20 & 44.4 & 26 & 65.0 \\
\hline Postgraduate student & 4 & 8.9 & 7 & 17.5 \\
\hline Employed & 18 & 40.0 & 4 & 10.0 \\
\hline No information available & 3 & 6.7 & 3 & 7.5 \\
\hline \multicolumn{5}{|l|}{ Employment } \\
\hline Full time student & 10 & 22.2 & 13 & 32.5 \\
\hline Working part time $(<50 \%)$ & 12 & 26.7 & 11 & 27.5 \\
\hline Working part time $(50-75 \%)$ & 3 & 6.7 & 1 & 2.5 \\
\hline Working full time (75-100\%) & 13 & 28.9 & 9 & 22.5 \\
\hline No information available & 7 & 15.6 & 6 & 15 \\
\hline \multicolumn{5}{|c|}{ Substance consumption within last 6 months } \\
\hline Smoking & 18 & 40 & 12 & 30 \\
\hline Cannabis products & 10 & 22.2 & 8 & 20 \\
\hline Alcohol (>one drink per week) & 16 & 35.6 & 18 & 45 \\
\hline Other illegal drugs & 7 & 15.6 & 3 & 7.5 \\
\hline \multicolumn{5}{|l|}{ Current subjective health rating } \\
\hline Excellent & 5 & 11.1 & 7 & 17.5 \\
\hline Very good & 15 & 33.3 & 14 & 35 \\
\hline Good & 17 & 37.8 & 15 & 37.5 \\
\hline Not so good & 8 & 17.8 & 4 & 10 \\
\hline $\mathrm{Bad}$ & 0 & 0 & 0 & 0 \\
\hline \multicolumn{5}{|l|}{ Chronic illnesses } \\
\hline Hyper-/Hypotension & 1 & 2.2 & 0 & 0 \\
\hline Cardiac disorders & 2 & 4.4 & 0 & 0 \\
\hline Respiratory disorders & 8 & 17.8 & 8 & 20 \\
\hline Gastrointestinal disorders & 0 & 0 & 2 & 5 \\
\hline Diabetes & 1 & 2.2 & 0 & 0 \\
\hline Neuronal disorders & 1 & 2.2 & 0 & 0 \\
\hline Allergies & 15 & 33.3 & 15 & 37.5 \\
\hline Mental disorders*,d & 13 & 28.9 & 1 & 2.5 \\
\hline Others & 14 & 31.1 & 8 & 20 \\
\hline
\end{tabular}

PBI: Parental Bonding Instrument; M: mean; CI: confidence Interval, CHF: Swiss Francs.

Displayed are means $(M)$ and $95 \%$ confidence intervals (95\% CI) for continuous data and number $(N)$ and percent $(\%)$ of participants for categorical data.

${ }^{\mathrm{a}}$ Missing values: $n=2$; ${ }^{\mathrm{b}}$ middle-sized leukocytes: monocytes, eosinophil granulocytes and basophil granulocytes; ${ }^{\mathrm{c}} \mathrm{Swiss}$ school system; ${ }^{\mathrm{d}}$ mainly depression.

*Significant group difference with $p<0.05$.

preliminary screening. We chose this subscale due to earlier studies identifying low maternal care as a strong risk factor for later mental health (Enns et al., 2002) and due to previous experiments investigating animal models of maternal care (Champagne et al., 2006; Weaver et al., 2004). A similar recruitment strategy was successfully applied in a previous study on maternal care in humans (Pruessner et al., 2004). For all analyses, participants were stratified into a high 
Figure 1. Flow chart of study participants included in data analyses $(N=85)$. From a screening sample, we recruited participants scoring very low or very high on the maternal subscale of the Parental Bonding Instrument (PBI) (see "Methods" section for details).

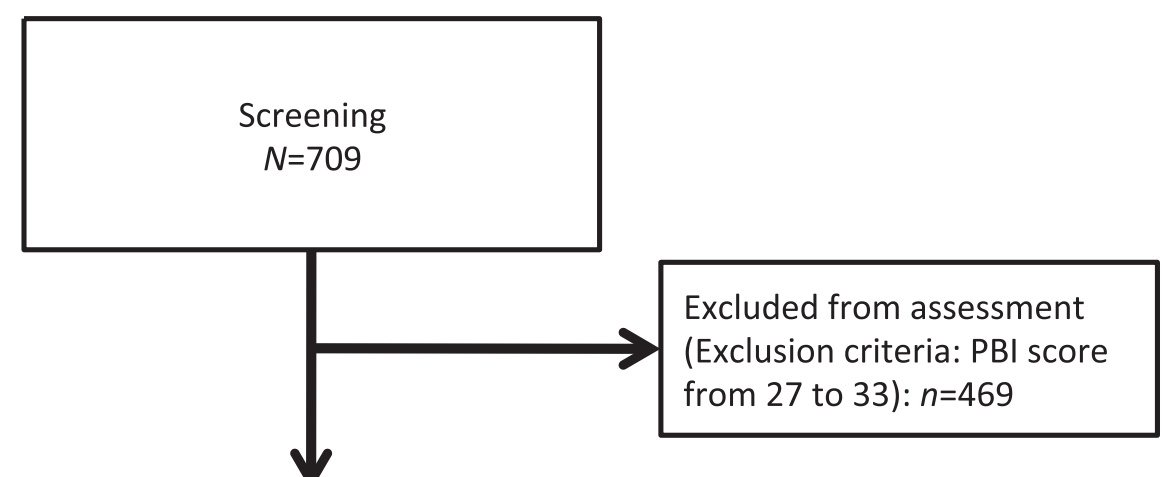

Invited for assessment Inclusion criteria: $\mathrm{PBI}$ score

Below cut-off (27): $n=132$

Above cut-off (33): $n=108$

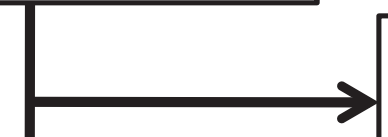

Lost to follow-up

Low maternal care: $n=85$

High maternal care: $n=66$
Participated at assessment

Low maternal care: $n=47$

High maternal care: $n=42$

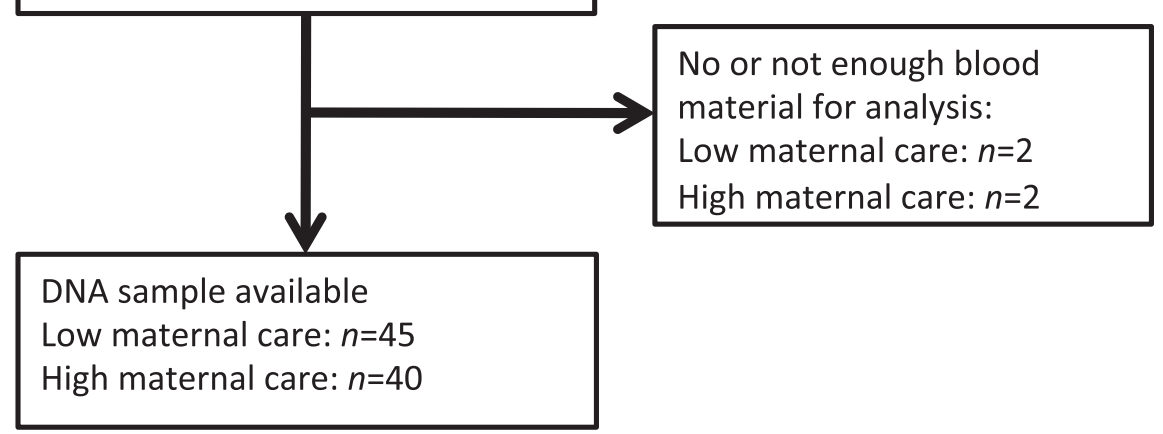

and a low maternal care group according to recruitment strategy.

Psychometric studies on the PBI maternal care score suggest a satisfactory validity and reliability in non-clinical samples, with Cronbach's alpha scores ranging from 0.85 to 0.91 (Brewin et al., 1992; Parker, 1989; Richman \& Flaherty, 1986). Reliability analyses in our sample yielded a Cronbach's alpha of 0.96 for the maternal care scale of the PBI, indicating high internal consistency.

Despite the retrospective nature of the questionnaire, a high stability over a 20-year period was demonstrated for the maternal care ratings in a previous study (retestcorrelation $=0.73,95 \% \quad \mathrm{CI}=0.62-0.84$ ) (Wilhelm et al., 2005). In a subsequent study, sex, lifetime history of depression, becoming a parent or number of reported life events did not influence the 20-year stability of maternal care ratings (Murphy et al., 2010). Although there seems to be an influence of experimentally induced depressed mood on maternal care ratings on the PBI (Gerlsma et al., 1992), a majority of studies on naturalistic mood states did not support a mood bias for the PBI (Gotlib et al., 1988; Parker, 1981).

Parenting validity studies on PBI maternal care scores reported correlations of $r=0.74$ for monozygotic and $r=0.63$ for dizygotic twin pairs (Parker, 1986). Furthermore, ratings of perceived maternal care were correlated with other instruments assessing parenting, such as the "Egna Minnen av Barndoms Uppfostran for adolescents" (EMBU-A) scale assessing maternal "emotional warmth" ( $r=0.64)$ (Gerlsma et al., 1991), or the "childhood experience of care and abuse questionnaire" (CECA-Q) scale for neglect $(r=-0.68)$ and antipathy $(r=-0.75)$ (Bifulco et al., 2005).

\section{Blood and DNA methylation analysis}

DNA was extracted from whole blood using Puregene (Qiagen, Venlo, The Netherlands) according to manufacturer's protocol. Samples were stored at $-80^{\circ} \mathrm{C}$ for subsequent DNA methylation analysis. 540 ng of genomic DNA was treated with sodium bisulfite using the EZ-96 DNA 
Methylation ${ }^{\mathrm{TM}}$ Kit (Zymo Research, Irvine, CA) according to manufacturer's standard protocol. For each run, four test samples of bisulfite converted DNA (single stranded) were quantified using NanoDrop (Thermo Scientific, Wilmington, $D E)$. Bisulfite polymerase chain reaction (PCR) amplification of one target sequence in $B D N F\left(B D N F_{T S}\right)$ and two target sequences in OXTR $\left(O X T R_{T S 1}, O X T R_{T S 2}\right)$ was conducted using Hot Star Taq DNA polymerase (Qiagen, Venlo, The Netherlands). The $B D N F_{T S}$ around the $3^{\prime}$-end of $B D N F$ exon VI is situated mainly within a $\mathrm{CpG}$ island - a region with a high density of $\mathrm{CpG}$ sites - that covers $B D N F$ exons $\mathrm{V}$, Vh and VI (Pruunsild et al., 2007). BDNF exon VI was selected due to its expression in the non-neuronal tissue of the periphery and its location within one of the $\mathrm{CpG}$ richest regions of the BDNF gene (Pruunsild et al., 2007; Timmusk et al., 1993). $O X T R_{T S 1}$ is located in the protein-coding region of $O X T R$ exon III; the $O X T R_{T S 2}$ partly covers the non-coding and protein-coding regions of OXTR exon III. Both target sequences were designed to cover parts of the OXTR CpG island comprising exons I to III (Kusui et al., 2001). Schematic diagrams of $B D N F$ and $O X T R$ with the exact location of target sequences are given in Figure 2. PCR products were inspected using gel-electrophoresis on $1.5 \%$ agarose gel. Samples were then prepared according to manufacturer's instructions for quantitative DNA methylation analysis using EpiTYPER 1.0 (Sequenom Inc., San Diego, CA). For each run, a fully methylated positive control (New England BioLabs ${ }^{\circledR}$ Inc., Ipswich, MA) and a blank control (distilled water) were included. The assays for the amplicons were designed using the Sequenom EpiDesigner software (San Diego, CA) (for information on primers, see supplementary information).

We analyzed blood cell count using Sysmex PocH-100i ${ }^{\mathrm{TM}}$ (Kobe, Japan). As only white blood cells have a nucleus containing DNA, we considered the relative number of leukocytes as potential mediators in the association between maternal care and DNA methylation, more specifically percentage of lymphocytes (small leukocytes), neutrophil granulocytes (large leukocytes) or middle-sized blood cells, consisting of monocytes, and eosinophil and basophil granulocytes.

\section{Statistical analysis}

The resolution of EpiTYPER yielded $\mathrm{CpG}$ units consisting of one to six individual $\mathrm{CpG}$ sites: $12 \mathrm{CpG}$ units for $B D N F_{T S}, 11$ CpG units for $O_{X T R_{T S 1}}$ and $28 \mathrm{CpG}$ units for $O X T R_{T S 2}$. All $\mathrm{CpG}$ sites underwent a quality control check in order to exclude potentially unreliable values, e.g. due to measuring inaccuracy or limitations by Sequenom: (i) One $\mathrm{CpG}$ unit in $B D N F_{T S}$, two CpG units in $O X T R_{T S 1}$ and one $\mathrm{CpG}$ unit in $O X T R_{T S 2}$ could not be measured due to upper or lower detection limits of Sequenom EpiTYPER. (ii) $\mathrm{CpG}$ units with $>20 \%$ missing data were excluded, which left $10 \mathrm{CpG}$ units for $B D N F_{T S}, 8 \mathrm{CpG}$ units for $O X T R_{T S 1}$ and $27 \mathrm{CpG}$ units for $O X T R_{T S 2}$. (iii) All $\mathrm{CpG}$ methylation values were compared with the values of the fully methylated positive control: if the value of the sample exceeded the value of the positive control, the value was set missing. All blank controls were negative. (iv) Finally, we identified potentially unreliable samples by setting outlier values as missing data ( $\geq 3$ standard deviations from mean methylation of the respective $\mathrm{CpG}$ unit). By conducting missing value analyses separately for each gene, participants with $>20 \%$ missing data were identified and excluded from the statistical analyses of the respective

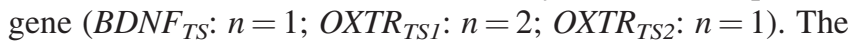
distribution of the raw data for each $\mathrm{CpG}$ is shown in Figure 3. Methylation values of $B D N F_{T S}$ and $O X T R_{T S 2}$ were ln-transformed to meet assumptions of normality $($ Methylation $=\ln (5 \% \mathrm{meC}$ methylation +0.02$)+4)$.

In $O_{X T R}$, CpG unit 3 and 4 had identical DNA methylation values. In $O X T R_{T S 2}$, DNA methylation values were identical for $\mathrm{CpG}$ unit 3 and 11, and for $\mathrm{CpG}$ unit 12, 14 and 21. Repeated values of the duplicate and triplicate $\mathrm{CpG}$ units had to be excluded to perform the mixed model analyses. In a last step, we identified $\mathrm{CpGs}$ with at least $1 \%$ interindividual variance and included them in the statistical analyses $\left(B_{D N F_{T S}:} 7 \mathrm{CpG}\right.$ units; OXTR ${ }_{T S 1}: 6 \mathrm{CpG}$ units; OXTR ${ }_{T S 2}: 17$ $\mathrm{CpG}$ units). We used a covariance pattern model (Fitzmaurice et al., 2011), a type of mixed model, to analyze associations between maternal care and DNA methylation for each target sequence separately. In covariance pattern models, the covariances among the repeated measures are modeled directly. The choice of the specific covariance pattern was based on the best model fit as indicated by the Akaike Information Criterion (AIC) and was "unstructured" for all target sequences (i.e. all variances and covariances were estimated independently).

We were particularly interested in the association of maternal care and DNA methylation of the target sequences, given repeated measures of CpGs and controlling for batch number, sex and age. These variables were included in all analyses due to their previously described associations with DNA methylation and parental care (Horvath et al., 2012; Tam \& Yeoh, 2008; Zhang et al., 2011). Therefore, our main model contained maternal care, age, sex and batch number as predictors and $\mathrm{CpG}$ unit as repeated measure variable. Sociodemographic variables with significant group differences (body mass index, income, mental disorders, see Table 1) were not associated with DNA methylation and therefore not investigated further (except for age and sex, see above).

Effects were tested using Log-Likelihood test, i.e. by comparing the fits of nested models including or excluding maternal care group, sex and age. In subsequent analyses, we investigated differential blood cell count in percent as a potential mediator, using a multilevel mediation model as suggested by Preacher and colleagues (2010).

Data preparation and data checks were conducted using IBM SPSS 20 (Armonk, NY). Covariance pattern models were analyzed using R, version 3.1.0 (R Development Core Team, 2014), including the package nlme (Pinheiro et al., 2013). Mediation models were calculated using the software Mplus6 (Los Angeles, CA) (Muthén \& Muthén, 1998-2011). An alpha level of $<0.05$ was considered significant. DNA methylation values are presented as percent of $5^{\prime}$ cytosine methylation $(\% 5 \mathrm{meC})$.

\section{Results}

In the $B D N F_{T S}$, DNA methylation was greater in the low maternal care group $(\operatorname{L-Ratio}(1)=4.47 ; p=0.035)$ as 
(A)

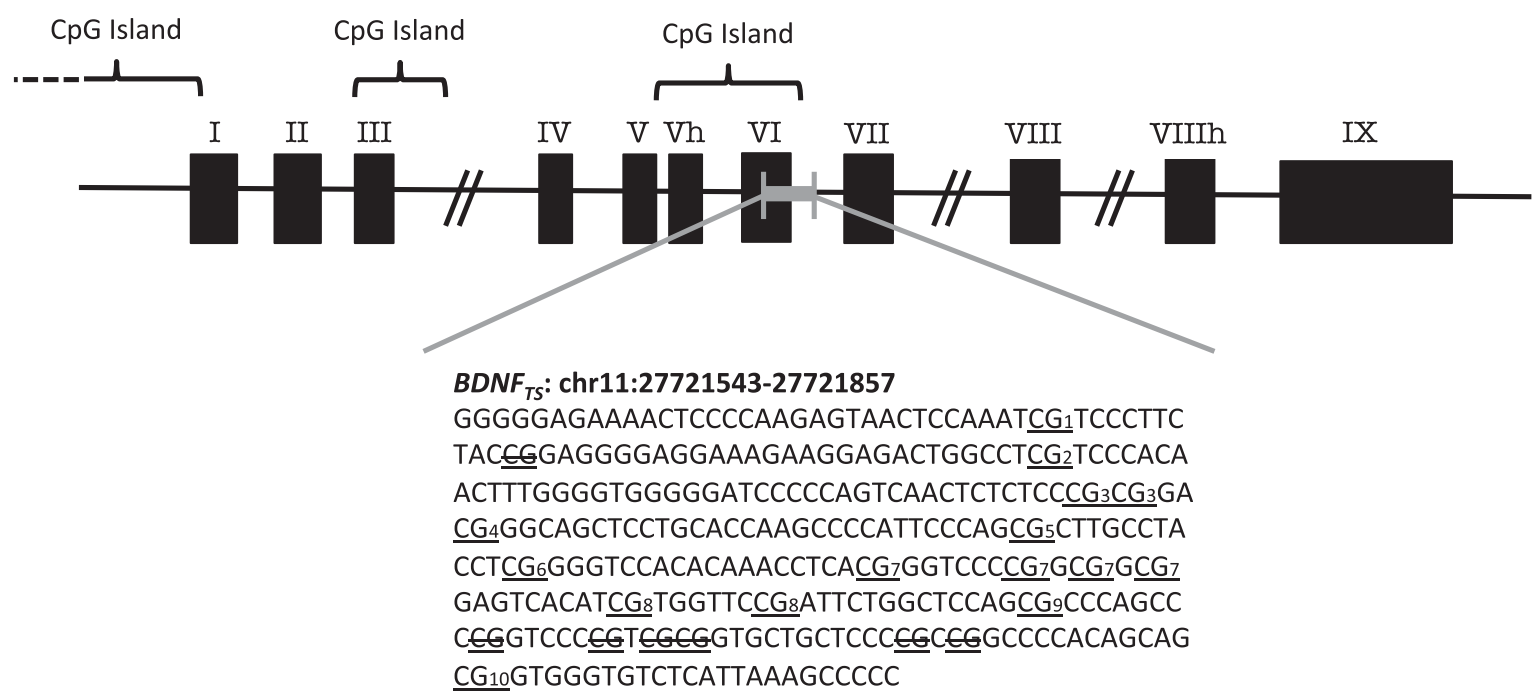

(B)

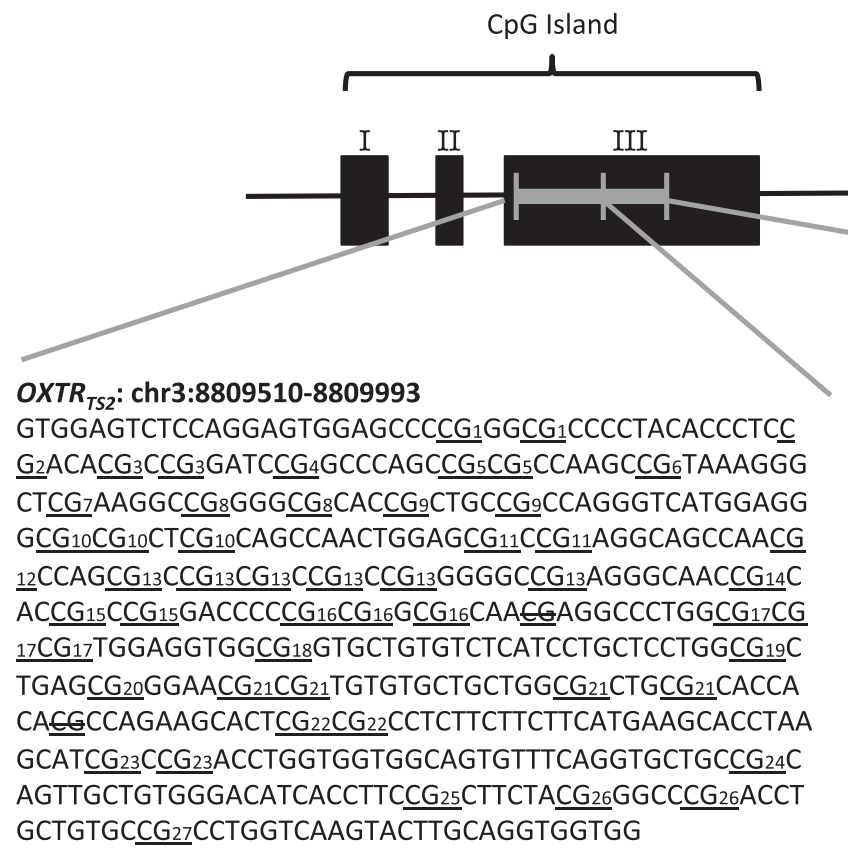

Figure 2. Schematic representation of the (A) BDNF and (B) OXTR gene with the target sequences investigated (in gray). The black boxes represent exons and the lines indicate introns. Exons are numbered consecutively with Roman numbers in the direction of transcription and correspond to the numbering described by Pruunsild et al. (2007) for BDNF or Kusui et al. (2001) for OXTR. CpG islands are shown in brackets, according to human genome browser at UCSC (Kent et al., 2002). The position of the three target sequence in the DNA and the exact base sequences are given below the respective genes. Underlined: $\mathrm{CpG}$ sites; struck through $\mathrm{CpG}$ sites: could not be analyzed due to high or low detection limits or $>20 \%$ missing data; $\mathrm{CpG}$ numbers: corresponding $\mathrm{CpG}$ unit number.

compared to the high maternal care group (Table 2). We found no effects for sex (L-Ratio(1) $=1.67 ; p=0.20)$ or age $($ L-Ratio $(1)=1.12 ; p=0.29)$. Although we did not find any effect of blood cell count on DNA methylation of the $B D N F_{T S}$ (all L-Ratios $<1.10$; all $p>0.29$ ), we investigated relative number of neutrophil granulocytes in mediation analyses for this target sequence. We did not find an indirect effect via relative number of neutrophil granulocytes (estimate $=-0.005 ; 95 \%$ confidence intervals $=-0.025$ to $0.015 ; p=0.63$ ) or a direct effect of maternal care on $B D N F_{T S}$ DNA methylation (estimate $=-0.067 ; 95 \%$ confidence intervals $=-0.147$ to $0.013 ; p=0.10)$.

In $O X T R_{T S 2}$, we found greater DNA methylation in the low compared to the high maternal care group (Likelihood Ratio(1) $=4.33 ; \quad p=0.04$ ) (Table 2). Additionally, we found a sex difference with men having lower DNA 
(A)

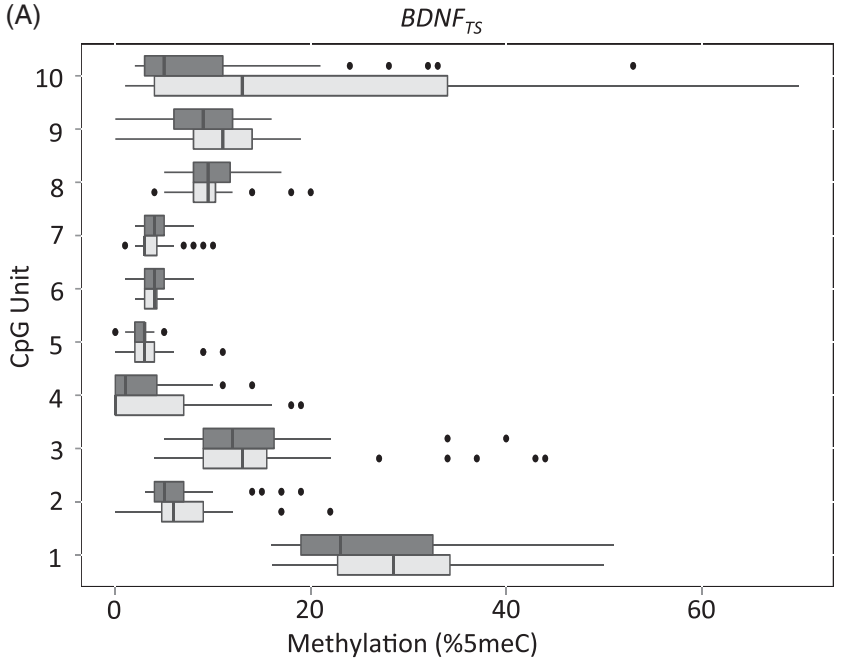

(B)

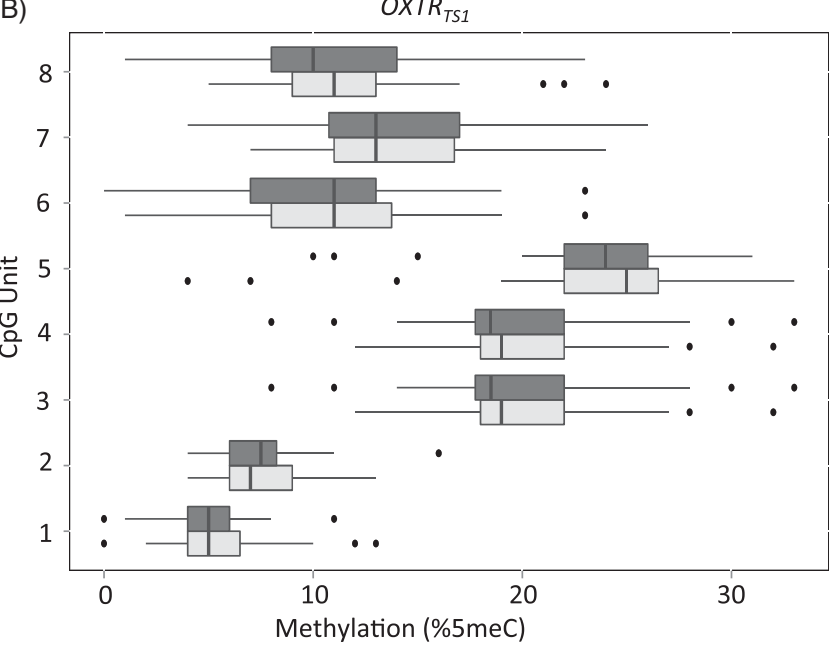

(C)

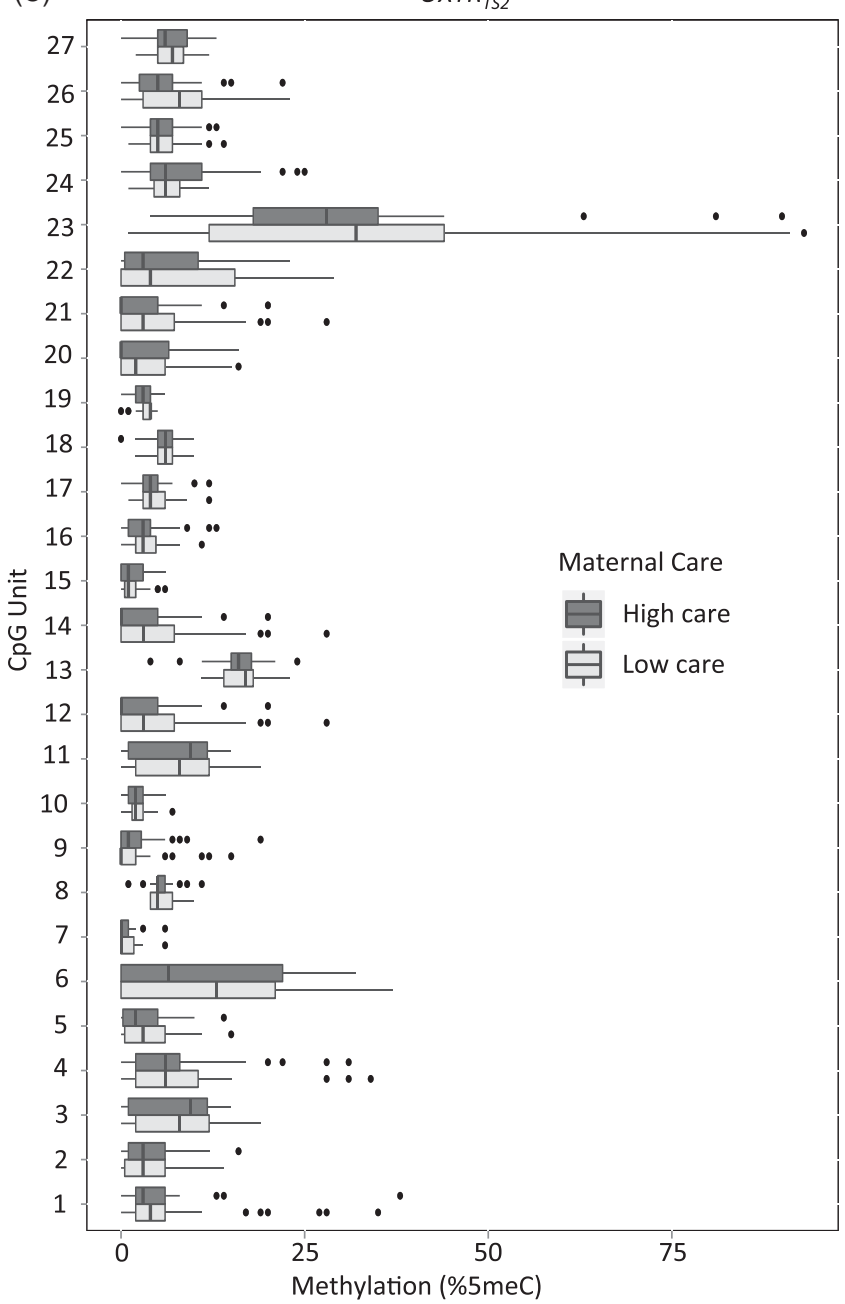

Figure 3. Box plots showing the distribution of untransformed DNA methylation $(\% 5 \mathrm{meC})$ of the (A) $B D N F_{T S}$, (B) OXTR ${ }_{T S 1}$ and (C) $O X T R_{T S 2}$ for high and low maternal care groups. CpG units yielded by Sequenom EpiTYPER are numbered consecutively. Black lines: median, box: percentiles 25-75, whiskers: percentiles 2.5-97.5, dots: outliers. BDNF: brain-derived neurotrophic factor gene; OXTR: oxytocin receptor gene; TS: target sequence; $\% 5 \mathrm{meC}$ : percent methylated $5^{\prime}$ methyl-cytosine; CpG: cytosine-guanine dinucleotide.

Table 2. Results obtained from mixed model analysis for each target sequence.

\begin{tabular}{|c|c|c|c|c|c|c|}
\hline & \multicolumn{2}{|c|}{ Maternal care group } & \multicolumn{4}{|c|}{ Model characteristics } \\
\hline & Value $^{\mathrm{a}}$ & $S E$ & L-Ratio & $p$ Value & $N$ & Observations \\
\hline$B D N F_{T S}$ & -0.071 & 0.033 & 4.470 & 0.035 & 78 & 531 \\
\hline$O_{T T R_{T S I}}$ & 0.025 & 3.698 & $<0.001$ & 0.995 & 83 & 495 \\
\hline $\operatorname{OXTR}_{T S 2}$ & -0.048 & 0.021 & 4.333 & 0.037 & 81 & 1325 \\
\hline
\end{tabular}

$B D N F$ : brain-derived neurotrophic factor; OXTR: oxytocin receptor; TS: target sequence; $S E$ : standard error; L-Ratio: Likelihood-Ratio.

Estimated effects of maternal care group include the values for estimated parameter effects of maternal care on DNA methylation and standarderrors $(S E)$. L-Ratio and $p$ values refer to the improvement in model fit, if the respective predictor (high care versus low care) was included in the model. Additionally, number of participants $(N)$ and number of observations are shown. All models included sex, age and batch number as covariates. DNA methylation values for $B D N F_{T S}$ and $O X T R_{T S 2}$ were transformed using natural logarithm transformation.

${ }^{a}$ Value corresponds to the difference in average DNA methylation between the low and high maternal care group, whereby low maternal care represents the reference group. methylation in $O X T R_{T S 2}$ compared to women (Likelihood Ratio(1) $=7.33 ; p=0.007)$ but no association of DNA methylation with age (Likelihood $\operatorname{Ratio}(1)=0.26 ; p=0.61$ ). In the mediation model, we examined relative number of neutrophil granulocytes as a potential mediator in the association between maternal care and DNA methylation of

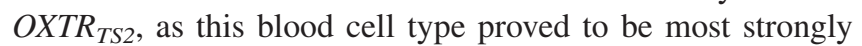
associated with DNA methylation (Likelihood Ratio(1) $=9.82 ; p=0.002$ ) compared to the other blood cell types. There was neither an indirect effect of maternal care on $O X T R_{T S 2}$ DNA methylation via relative number of neutrophil granulocytes (estimate $=-0.015$; $95 \%$ confidence intervals $=-0.038$ to $0.008 ; p=0.19$ ), nor a direct effect (estimate $=-0.029 ; \quad 95 \%$ confidence intervals $=-0.107$ to $0.031 ; p=0.34)$.

In $O X T R_{T S 1}$, DNA methylation did not differ between maternal care groups $(\operatorname{L-Ratio}(1)=0.00004 ; \quad p=0.99)$. We found no effects for $\operatorname{sex}(\operatorname{L-Ratio}(1)=1.06 ; p=0.30)$ or age $(\mathrm{L}-\operatorname{Ratio}(1)=0.39 ; \quad p=0.53)$. However, there was 
an effect for the relative number of middle-sized blood cells $(\mathrm{L}-\operatorname{Ratio}(1)=4.80, p=0.03)$.

In Figure 3, we illustrate distribution of the DNA methylation values as yielded by Sequenom EpiTYPER (San Diego, CA). We provide test statistics and further details, such as means, standard errors and inter-individual variance for each individual $\mathrm{CpG}$ unit as well as mean differences between maternal care groups in supplementary Table 1.

\section{Discussion}

We examined DNA methylation of two stress-related candidate genes - one target sequence in BDNF and two target sequences in $O X T R$ - in peripheral blood of adults reporting high or low maternal care during childhood and adolescence. We found that low maternal care was associated with greater whole blood DNA methylation of the $B D N F_{T S}$ and the $O X T R_{T S 2}$ compared to high maternal care. We did not find any indication that the associations of maternal care with $B D N F_{T S}$ or $O X T R_{T S 2}$ DNA methylation were mediated by differential blood cell count. Moreover, the results did not substantially change after controlling for symptoms of depression (data not shown). We did not find any maternal care-related differences in DNA methylation in $O X T R_{T S 1}$.

Greater DNA methylation in the BDNF and $O X T R_{T S 2}$ in participants reporting low compared to those reporting high maternal care provides evidence for epigenetic changes related to early adverse experiences. As BDNF functioning is implicated in neuronal development and neuroprotection (Binder \& Scharfman, 2004; Kerschensteiner et al., 1999) and the oxytocin system is involved in the dampening of the stress response (Carter, 2003), we speculate that maternal care-associated changes in DNA methylation of the OXTR might provide a potential mechanism contributing to the differences in stress-reactivity (Engert et al., 2010) and the increased risk to develop a mental disorder later in life after experiences of low parental care (Enns et al., 2002). Of note, the differences in DNA methylation between high and low maternal care were small and the rationale for using peripheral blood as indicators of processes in the central nervous system is still under debate. Although DNA methylation differs greatly between cell types, environmentally induced alterations in DNA methylation might affect different kinds of cells similarly (Davies et al., 2012; Kundakovic et al., 2015). Our results are in line with (i) Perroud et al. (2013) reporting aberrant BDNF DNA methylation in human peripheral blood cells after experiences of early maltreatment, and (ii) findings by Cecil et al. (2014) demonstrating an association between parental risks at the age of 8 to 9 years (e.g. parental psychopathology) and OXTR DNA methylation in peripheral blood of children with internalizing problems at 9 years. However, previous studies did not investigate the same target sequences as were studied here.

In the $B D N F_{T S}$ and $O X T R_{T S 2}$, the indirect and direct effect from the mediation model were both non-significant indicating that neither the relative number of neutrophil granulocytes is a mediator in the association between maternal care and DNA methylation of $O X T R_{T S 2}$, nor does maternal care simply have a direct impact on DNA methylation, despite a total effect. This finding emphasizes the need to scrutinize further potential mediators, since additional variables could mediate the association between maternal care and DNA methylation in $O X T R_{T S 2}$. Finally, it seems that differences in DNA methylation in the OXTR were limited to the $O X T R_{T S 2}$ target sequence, as we did not find any maternal care-related differences in $O X T R_{T S 1}$.

Low maternal care did not predict DNA methylation of OXTR $_{T S 1}$. In a previous study by our group, DNA methylation changes were related to acute psychosocial stress in the same assessed $O X T R_{T S 1}$ target sequence (Unternaehrer et al., 2012), which was independent from stress-related changes in blood cell count. Therefore, we hypothesize that DNA methylation in this target sequence could be more sensitive to acute psychosocial stress as compared to early life stress. Finally, we found greater $O X T R_{T S 2}$ DNA methylation in women compared to men.

Although the purpose of this study was not to analyze specific CpG units individually, we emphasize the strong DNA methylation difference between the maternal care groups in $\mathrm{CpG}$ unit 9 and 10 of the $B D N F_{T S}$ (supplementary Table 1), which is located at an mRNA polymerase 2 binding site and could therefore have direct functional consequences for $B D N F$ transcription (Kent et al., 2002; Meyer et al., 2013).

In sum, previous studies have indicated epigenetic alterations by early life stress in several stress-related genes across the whole genome animal and human. In this study, we extended these findings to altered DNA methylation in a $B D N F$ and an OXTR target sequence measured in human peripheral blood cells. Several key questions should be addressed in future studies: (i) Is DNA methylation in these target sequences associated with peripheral BDNF or OXTR mRNA levels? and (ii) What is the specific functional relevance of these sequences with special regard to the effects of maternal care on mental health?

This study has several strengths. First, we considered blood cell count as a potential mediator in the association between maternal care and DNA methylation. Second, due to the inclusion of two candidate genes and two different target sequences within one of the genes, the findings indicate that maternal care-related differences in DNA methylation might depend on the investigated target sequences. Lastly, as the present data are hierarchical, with $\mathrm{CpG}$ units nested within genes, the use of covariance pattern models appears to represent a valuable extension to simpler models in which methylation values are first aggregated across $\mathrm{CpGs}$ and then analyzed using standard models like ANOVA or ANCOVA, which do not consider the internal consistency of $\mathrm{CpG}$ units. Indeed, our results suggest that $\mathrm{CpG}$ units exhibited different variances and covariances.

This study has the following limitations: First, due to the cross-sectional nature of the study, differences in DNA methylation between retrospectively assessed high and low maternal care cannot be interpreted causally. Second, an adverse maternal environment often comes with additional potentially stressful environmental factors, which could be linked to changes in DNA methylation. Furthermore, we did not assess current levels of stress, although $O X T R_{T S 2}$ showed some dynamic changes after acute psychosocial stress in our 
previous study (Unternaehrer et al., 2012). Third, we did not confirm whether the participant's primary care person was the mother but specifically examined maternal care as predictor of DNA methylation. Fourth, maternal care was assessed using retrospective data and although studies on the psychometric properties of the PBI suggest a good retest stability, reliability and validity for this questionnaire (see "Methods" section), we cannot completely rule out residual bias by age, sex, mood or stress experience: (i) our sample included 10 participants over the age of 40 years and there are no studies investigating the stability of the PBI over a period that is longer than 20 years. Indeed, we found that participants in the low maternal care groups were older compared to the high maternal care group; (ii) we did not find any sex differences in the PBI scores, indicating no sex bias in our sample; (iii) we did not assess current state of mood or stress levels at the time of PBI completion, and thus cannot rule out that mood or current stress levels biased the PBI ratings. Fifth, DNA methylation was measured in peripheral blood and findings cannot be translated into neuronal or other tissue types, although there is evidence that DNA methylation of some genes might be correlated across tissue (Davies et al., 2012). Additionally, $B D N F$ is a complex gene with multiple exons and promoters. Although previous studies examining stress- or mental healthrelated differences in $B D N F$ in the human periphery focused on exon I or exon IV (D'Addario et al., 2012; Dell'Osso et al., 2014; Fuchikami et al., 2011; Kang et al., 2013; Perroud et al., 2013), we decided to examine a less studied region in $B D N F$ exon VI. BDNF exons I and IV are mainly expressed in neuronal tissue (Pruunsild et al., 2007; Timmusk et al., 1993), while BDNF exon VI transcripts are abundant across multiple peripheral tissues as well as neuronal tissue (Pruunsild et al., 2007). Previously, DNA methylation of $B D N F$ exon VI was associated with maternal smoking during pregnancy in blood samples of adolescent offspring (ToledoRodriguez et al., 2010). Therefore, exon VI seemed a promising candidate region to study in the available peripheral blood specimen. Notably, findings published after data collection for the present study suggest that DNA methylation of BDNF exon I as measured in the periphery could be used to estimate DNA methylation of the same gene regions in the brain (Stenz et al., 2015), making BDNF exon I another interesting candidate region. Sixth, the sample was derived from an ad-hoc student sample and might not be representative of the general population. Therefore, the study should be replicated in a larger, potentially more generalizable sample. Last, mediation analyses should be replicated in a study with a greater sample size, as our data set produced instable results (i.e. we found only a trend for the direct effect of maternal care on $O X T R_{T S 2}$ DNA methylation in the mediation models). Additionally, the use of multilevel structural equation models explicitly taking measurement errors into account might further improve statistical models for this type of data.

\section{Conclusions}

In conclusion, DNA methylation in a BDNF and one OXTR target sequence was greater in peripheral blood of adults reporting low compared to those reporting high maternal care during childhood and adolescence. These results could improve the understanding of how maternal care influences the epiphenotype in humans.

\section{Acknowledgements}

We thank all people involved in data collection and entry, especially Michael Pluess, Nicole Oehninger, Gina Retschnig, Petra Hagmaier and Simone Briner, as well as everyone supporting the biological analyses in the Laboratories in Basel, including Sigrid Falk, Fabian Peter, Melanie Knabe and Laura Landi, and the staff at the laboratories of the "MRC Social, Genetics and Developmental Psychiatry center" of King's College in London, especially Jonathan Mill.

\section{Declaration of interest}

The authors report no conflict of interest. The authors alone are responsible for the content and writing of the paper. Sources of funding and support: This work is part of the National Centre of Competence in Research (NCCR), Swiss Etiological Study of Adjustment and Mental Health (sesam). The Swiss National Science Foundation (SNSF) (project no. 51A240-104890), the University of Basel, the F. HoffmannLa Roche Corp., and the Freie Akademische Gesellschaft provided core support for the NCCR sesam. Additionally, G.M. receives SNSF funding and E.U. was supported by the SNSF, project no. 100014_135328. Furthermore, GM receives funding from the Korea Research Foundation within the Global Research Network Program (project no. 2013S1A2A2035364). The funders had no role in study design, in the collection, analysis, and interpretation of data, in the writing of the report, and in the decision to submit the paper for publication.

\section{References}

Adalsteinsson BT, Gudnason H, Aspelund T, Harris TB, Launer LJ, Eiriksdottir G, Smith AV, Gudnason V. (2012). Heterogeneity in white blood cells has potential to confound DNA methylation measurements. PLoS One 7(10):e46705.

Albers EM, Riksen-Walraven JM, Sweep FCGJ, de Weerth C. (2008). Maternal behavior predicts infant cortisol recovery from a mild everyday stressor. J Child Psychol Psyc 49(1):97-103.

Auclair G, Weber M. (2012). Mechanisms of DNA methylation and demethylation in mammals. Biochimie 94(11):2202-11.

Belsky J, de Haan M. (2011). Annual research review: parenting and children's brain development: the end of the beginning. J Child Psychol Psychiatry 52(4):409-28.

Bick J, Naumova O, Hunter S, Barbot B, Lee M, Luthar SS, Raefski A, Grigorenko EL. (2012). Childhood adversity and DNA methylation of genes involved in the hypothalamus-pituitary-adrenal axis and immune system: whole-genome and candidate-gene associations. Dev Psychopathol 24(4):1417-25.

Bifulco A, Bernazzani O, Moran RM, Jacobs C. (2005). The childhood experience of care and abuse questionnaire (CECA.Q): validation in a community series. Br J Clin Psychol 44:563-81.

Binder DK, Scharfman HE. (2004). Brain-derived neurotrophic factor. Growth Factors 22(3):123-31.

Bowlby J. (1969). Attachment and loss. New York: Basic Books.

Brewin CR, Firth-Cozens J, Furnham A, McManus C. (1992). Selfcriticism in adulthood and recalled childhood experience. J Abnorm Psychol 101(3):561-6.

Carter CS. (2003). Developmental consequences of oxytocin. Physiol Behav 79(3):383-97.

Cecil CA, Lysenko LJ, Jaffee SR, Pingault JB, Smith RG, Relton CL, Woodward G, et al. (2014). Environmental risk, Oxytocin Receptor 
Gene (OXTR) methylation and youth callous-unemotional traits: a 13-year longitudinal study. Mol Psychiatry 19(10):1071-7.

Champagne FA, Weaver IC, Diorio J, Dymov S, Szyf M, Meaney MJ. (2006). Maternal care associated with methylation of the estrogen receptor-alphalb promoter and estrogen receptor-alpha expression in the medial preoptic area of female offspring. Endocrinology 147(6): 2909-15.

D’Addario C, Dell'Osso B, Palazzo MC, Benatti B, Lietti L, Cattaneo E, Galimberti D, et al. (2012). Selective DNA methylation of BDNF promoter in bipolar disorder: differences among patients with BDI and BDII. Neuropsychopharmacology 37(7):1647-55.

Dadds MR, Moul C, Cauchi A, Dobson-Stone C, Hawes DJ, Brennan J, Ebstein RE. (2014). Methylation of the oxytocin receptor gene and oxytocin blood levels in the development of psychopathy. Dev Psychopathol 26(1):33-40.

Davies MN, Volta M, Pidsley R, Lunnon K, Dixit A, Lovestone S, Coarfa C, et al. (2012). Functional annotation of the human brain methylome identifies tissue-specific epigenetic variation across brain and blood. Genome Biol 13(6):R43.

Dell'Osso B, D'Addario C, Carlotta Palazzo M, Benatti B, Camuri G, Galimberti D, Fenoglio C, et al. (2014). Epigenetic modulation of BDNF gene: differences in DNA methylation between unipolar and bipolar patients. J Affect Disord 166:330-3.

Engert V, Buss C, Khalili-Mahani N, Wadiwalla M, Dedovic K, Pruessner JC. (2010). Investigating the association between early life parental care and stress responsivity in adulthood. Dev Neuropsychol 35(5):570-81.

Enns MW, Cox BJ, Clara I. (2002). Parental bonding and adult psychopathology: results from the US National Comorbidity Survey. Psychol Med 32(6):997-1008.

Fitzmaurice GM, Laird NM, Ware JH. (2011). Applied longitudinal analysis. 2nd ed. Hoboken: Wiley.

Fuchikami M, Morinobu S, Segawa M, Okamoto Y, Yamawaki S, Ozaki $\mathrm{N}$, Inoue T, et al. (2011). DNA methylation profiles of the brainderived neurotrophic factor (BDNF) gene as a potent diagnostic biomarker in major depression. PLoS One 6(8):e23881.

Gerlsma C, Arrindell WA, Vanderveen N, Emmelkamp PMG. (1991). A parental rearing style questionnaire for use with adolescents psychometric evaluation of the EMBU-A. Pers Individ Dif 12(12): 1245-53.

Gerlsma C, Mosterman I, Buwalda S, Emmelkamp PMG. (1992). Mood and memories of parental rearing styles - a comparison of mood effects on questionnaire-cued and free-recall of autobiographical memories. J Psychopathol Behav Assess 14(4):343-61.

Gotlib IH, Mount JH, Cordy NI, Whiffen VE. (1988). Depression and perceptions of early parenting - a longitudinal investigation. Br J Psychiatry 152:24-7.

Gregory SG, Connelly JJ, Towers AJ, Johnson J, Biscocho D, Markunas CA, Lintas C, et al. (2009). Genomic and epigenetic evidence for oxytocin receptor deficiency in autism. BMC Med 7:62.

Heim C, Young LJ, Newport DJ, Mletzko T, Miller AH, Nemeroff CB. (2009). Lower CSF oxytocin concentrations in women with a history of childhood abuse. Mol Psychiatry 14(10):954-8.

Horvath S, Zhang Y, Langfelder P, Kahn RS, Boks MP, van Eijk K, van den Berg LH, Ophoff RA. (2012). Aging effects on DNA methylation modules in human brain and blood tissue. Genome Biol 13(10):R97.

Jack A, Connelly JJ, Morris JP. (2012). DNA methylation of the oxytocin receptor gene predicts neural response to ambiguous social stimuli. Front Hum Neurosci 6:Article no. 280, 7 pages.

Kang HJ, Kim JM, Lee JY, Kim SY, Bae KY, Kim SW, Shin IS, et al. (2013). BDNF promoter methylation and suicidal behavior in depressive patients. J Affect Disord 151(2):679-85.

Keller S, Sarchiapone M, Zarrilli F, Videtic A, Ferraro A, Carli V, Sacchetti S, et al. (2010). Increased BDNF promoter methylation in the Wernicke area of suicide subjects. Arch Gen Psychiatry 67(3): $258-67$.

Kent WJ, Sugnet CW, Furey TS, Roskin KM, Pringle TH, Zahler AM, Haussler D. (2002). The human genome browser at UCSC. Genome Res 12(6):996-1006.

Kerschensteiner M, Gallmeier E, Behrens L, Leal VV, Misgeld T, Klinkert WE, Kolbeck R, et al. (1999). Activated human T cells, $\mathrm{B}$ cells, and monocytes produce brain-derived neurotrophic factor in vitro and in inflammatory brain lesions: a neuroprotective role of inflammation? J Exp Med 189(5):865-70.
Knappe S, Beesdo-Baum K, Fehm L, Lieb R, Wittchen HU. (2012). Characterizing the association between parenting and adolescent social phobia. J Anxiety Disord 26(5):608-16.

Kundakovic M, Gudsnuk K, Herbstman JB, Tang D, Perera FP, Champagne FA. (2015). DNA methylation of BDNF as a biomarker of early-life adversity. Proc Natl Acad Sci U S A 112(22):6807-13.

Kusui C, Kimura T, Ogita K, Nakamura H, Matsumura Y, Koyama M, Azuma C, Murata Y. (2001). DNA methylation of the human oxytocin receptor gene promoter regulates tissue-specific gene suppression. Biochem Biophys Res Commun 289(3):681-6.

McGowan PO, Sasaki A, D'Alessio AC, Dymov S, Labonte B, Szyf M, Turecki G, Meaney MJ. (2009). Epigenetic regulation of the glucocorticoid receptor in human brain associates with childhood abuse. Nat Neurosci 12(3):342-8.

McGowan PO, Sasaki A, Huang TC, Unterberger A, Suderman M, Ernst C, Meaney MJ, et al. (2008). Promoter-wide hypermethylation of the ribosomal RNA gene promoter in the suicide brain. PLoS One 3(5): e2085.

McGowan PO, Suderman M, Sasaki A, Huang TC, Hallett M, Meaney MJ, Szyf M. (2011). Broad epigenetic signature of maternal care in the brain of adult rats. PLoS One 6(2):e14739.

Meinlschmidt G, Heim C. (2007). Sensitivity to intranasal oxytocin in adult men with early parental separation. Biol Psychiatry 61(9): $1109-11$.

Meyer LR, Zweig AS, Hinrichs AS, Karolchik D, Kuhn RM, Wong M, Sloan CA, et al. (2013). The UCSC Genome Browser database: extensions and updates 2013. Nucleic Acids Res 41(Database issue): D64-9.

Murgatroyd C, Patchev AV, Wu Y, Micale V, Bockmuhl Y, Fischer D, Holsboer F, et al. (2009). Dynamic DNA methylation programs persistent adverse effects of early-life stress. Nat Neurosci 12(12): 1559-66.

Murphy E, Wickramaratne P, Weissman M. (2010). The stability of parental bonding reports: a 20-year follow-up. J Affect Disord 125(1-3):307-15

Muthén LK, Muthén BO. (1998-2011). Mplus user's guide. 6th ed. Los Angeles, CA: Muthén \& Muthén.

Naumova OY, Lee M, Koposov R, Szyf M, Dozier M, Grigorenko EL. (2012). Differential patterns of whole-genome DNA methylation in institutionalized children and children raised by their biological parents. Dev Psychopathol 24(1):143-55.

Parker G. (1981). Parental reports of depressives - an investigation of several explanations. J Affect Disord 3(2):131-40.

Parker G. (1986). Validating an experiential measure of parental style the use of a twin sample. Acta Psychiatr Scand 73(1):22-7.

Parker G. (1989). The Parental Bonding Instrument: psychometric properties reviewed. Psychiatr Dev 7(4):317-35.

Parker G, Tupling H, Brown LB. (1979). A parental bonding instrument. Br J Med Psychol 52(Mar):1-10.

Perroud N, Paoloni-Giacobino A, Prada P, Olie E, Salzmann A, Nicastro $\mathrm{R}$, Guillaume S, et al. (2011). Increased methylation of glucocorticoid receptor gene (NR3C1) in adults with a history of childhood maltreatment: a link with the severity and type of trauma. Transl Psychiatry 1:e59.

Perroud N, Salzmann A, Prada P, Nicastro R, Hoeppli ME, Furrer S, Ardu S, et al. (2013). Response to psychotherapy in borderline personality disorder and methylation status of the BDNF gene. Transl Psychiatry 3:e207

Petersson M, Lundeberg T, Uvnas-Moberg K. (1999). Short-term increase and long-term decrease of blood pressure in response to oxytocin-potentiating effect of female steroid hormones. J Cardiovasc Pharmacol 33(1):102-8

Pinheiro J, Bates D, DebRoy S, Sarkar D, R Development Core Team. (2013). nlme: linear and nonlinear mixed effects models. R package version 3.1-109. Available at http://cran.r-project.org/web/packages/ nlme/index.html.

Preacher KJ, Zyphur MJ, Zhang Z. (2010). A general multilevel SEM framework for assessing multilevel mediation. Psychol Methods 15(3):209-33.

Pruessner JC, Champagne F, Meaney MJ, Dagher A. (2004). Dopamine release in response to a psychological stress in humans and its relationship to early life maternal care: a positron emission tomography study using [11C]raclopride. J Neurosci 24(11): $2825-31$. 
Pruunsild P, Kazantseva A, Aid T, Palm K, Timmusk T. (2007). Dissecting the human BDNF locus: bidirectional transcription, complex splicing, and multiple promoters. Genomics 90(3): 397-406.

R Development Core Team. (2014). R: a language and environment for statistical computing. Vienna, Austria: R Foundation for Statistical Computing.

Richman JA, Flaherty JA. (1986). Childhood relationships, adult coping resources and depression. Soc Sci Med 23(7):709-16.

Roth TL, Lubin FD, Funk AJ, Sweatt JD. (2009). Lasting epigenetic influence of early-life adversity on the BDNF gene. Biol Psychiatry 65(9):760-9.

Russell JA, Leng G, Douglas AJ. (2003). The magnocellular oxytocin system, the fount of maternity: adaptations in pregnancy. Front Neuroendocrin 24(1):27-61.

Stenz L, Zewdie S, Laforge-Escarra T, Prados J, La Harpe R, Dayer A, Paoloni-Giacobino A, et al. (2015). BDNF promoter I methylation correlates between post-mortem human peripheral and brain tissues. Neurosci Res 91:1-7.

Surtees P, Wainwright N, Day N, Brayne C, Luben R, Khaw KT. (2003). Adverse experience in childhood as a developmental risk factor for altered immune status in adulthood. Int J Behav Med 10(3): 251-68.

Tam CL, Yeoh SH. (2008). Parental bonding and parent childrelationship among tertiary level students. Sunway Acad J 5:111-28.

Timmusk T, Palm K, Metsis M, Reintam T, Paalme V, Saarma M, Persson H. (1993). Multiple promoters direct tissue-specific expression of the rat BDNF gene. Neuron 10(3):475-89.

Toledo-Rodriguez M, Lotfipour S, Leonard G, Perron M, Richer L, Veillette S, Pausova Z, Paus T. (2010). Maternal smoking during pregnancy is associated with epigenetic modifications of the brain- derived neurotrophic factor-6 exon in adolescent offspring. Am J Med Genet B Neuropsychiatr Genet 153B(7):1350-4.

Tyrka AR, Price LH, Marsit C, Walters OC, Carpenter LL. (2012). Childhood adversity and epigenetic modulation of the leukocyte glucocorticoid receptor: preliminary findings in healthy adults. PLoS One 7(1):e30148.

Unternaehrer E, Luers P, Mill J, Dempster E, Meyer AH, Staehli S, Lieb R, et al. (2012). Dynamic changes in DNA methylation of stressassociated genes (OXTR, BDNF) after acute psychosocial stress. Transl Psychiatry 2:e150.

Uvnas-Moberg K. (1998). Oxytocin may mediate the benefits of positive social interaction and emotions. Psychoneuroendocrinology 23(8): $819-35$.

Weaver ICG, Cervoni N, Champagne FA, D'Alessio AC, Sharma Jr S, Dymov S, Szyf M, Meaney MJ. (2004). Epigenetic programming by maternal behavior. Nat Neurosci 7(8):847-54.

Wilhelm K, Niven H, Parker G, Hadzi-Pavlovic D. (2005). The stability of the Parental Bonding Instrument over a 20-year period. Psychol Med 35(3):387-93.

Zhang FF, Cardarelli R, Carroll J, Fulda KG, Kaur M, Gonzalez K, Vishwanatha JK, et al. (2011). Significant differences in global genomic DNA methylation by gender and race/ethnicity in peripheral blood. Epigenetics 6(5):623-9.

Zhang TY, Hellstrom IC, Bagot RC, Wen X, Diorio J, Meaney MJ. (2010). Maternal care and DNA methylation of a glutamic acid decarboxylase 1 promoter in rat hippocampus. J Neurosci 30(39): 13130-7.

Zhang Y, Labonte B, Wen XL, Turecki G, Meaney MJ. (2013). Epigenetic mechanisms for the early environmental regulation of hippocampal glucocorticoid receptor gene expression in rodents and humans. Neuropsychopharmacology 38(1):111-23. 